\title{
EQUINUS DEFORMITY IN CEREBRAL PALSY
}

\section{A Comparison between Elongation of the Tendo Calcaneus and Gastrocnemius Recession}

\author{
W. J. W. Sharrard and S. Bernstein, * Sheffield, England \\ From the Children's Hospital, Sheffield, and the University Department of Orthopaedics of Sheffield
}

Equinus is one of the deformities most often met in children with cerebral palsy (McCarroll and Schwartzmann 1943; Pollock 1953, 1962; Silver and Simon 1959). Action that can be taken to diminish equinus deformity includes repeated passive stretching, manipulation, bracing, splintage and denervation of components of the triceps surae (Stoffel 1913) or lengthening it surgically. It is the authors' belief that, once true shortening of the triceps surae has developed to an extent that prevents ankle extension above a right angle even under anaesthesia, conservative measures will not prevent further deformity. Partial denervation may weaken the triceps surae enough to prevent further deformity but will not lengthen the muscle.

This study compares elongation of the tendo calcaneus with recession of the gastrocnemius tendons as described by Vulpius and Stoffel $(1920)$ and Strayer $(1950,1958)$. Proximal release of the gastrocnemius origin as described by Silfverskiöld (1924) was rarely done in this series and its results are not considered here.

Most accounts of the treatment of equinus by operation advise prolonged bracing or splintage to maintain the correction until the child is fully grown (Barnett 1952, Pollock 1953, Phelps 1957, Bassett and Baker 1966). Because we believe that the primary cause of the equinus arises from the unbalanced action of extensor and flexor muscles and that elongation of the triceps surae sufficiently weakens it to restore balanced action, no bracing or splintage was used after the initial three to five weeks of plaster immobilisation. Failure to brace has resulted in no greater rate of recurrence than is recorded by others in the literature.

\section{MATERIAL}

Between 1954 and 1965 ninety-two patients with cerebral palsy had operations for equinus at Sheffield Children's Hospital. Their notes were reviewed and a follow-up examination was made of fifty-seven patients. One patient had died and thirty-four could not be traced. Forty of those who attended were over fifteen years of age and seventeen were between ten and fourteen years; their average age was sixteen years and four months and the average time since the last operation for equinus was eight years and nine months. The records of all the ninetytwo patients were used to determine how often the deformity recurred and needed a second or third operation, but the end-results are reported only for the fifty-seven patients seen at follow-up. The examination showed whether the equinus deformity had recurred or not and if there was a calcaneus gait or calcaneus deformity and, in those treated by gastrocnemius recession, any weakness of knee flexion. A general assessment was also made of the gait in relation to the function of the ankle and foot.

\section{THE OPERATIONS: INDICATIONS AND TECHNIQUE}

The indication for lengthening of the tendo calcaneus was an equinus deformity that prevented passive extension beyond the right angle even when the knee was flexed. The

* Orthopaedic Research and Education Foundation Carlberg Travelling Fellow. 
operation was done through a postero-lateral incision, the tendo calcaneus being elongated by a coronal incision and the tendon sutured with the ankle held at a right angle. Immobilisation was sometimes by a groin-to-toe plaster, but more usually by a below-knee plaster and was generally kept for at least three weeks but not more than six weeks.

Gastrocnemius recession was done through a midline incision in the upper third of the calf. The gastrocnemius tendons were identified where they gained insertion into the soleus aponeurosis. The tendons were divided and the gastrocnemius bellies were mobilised proximally until they were free of all attachment to the soleus. They were not sutured but were allowed to find their own level. The limb was immobilised with the knee extended and the ankle extended to a right angle for three to five weeks. After removal of the plaster physiotherapy was given to encourage active extension and flexion. The patient was allowed to walk-if he was able to-as soon as possible.

TABLE I

Operations for Equinus Deformity in Ninety-two Patients

\begin{tabular}{|l|c|c|c|c|}
\hline \multicolumn{1}{|c|}{ Operation } & Extremities & $\begin{array}{c}\text { Bilateral } \\
\text { operation }\end{array}$ & $\begin{array}{c}\text { Associated } \\
\text { operations }\end{array}$ & $\begin{array}{c}\text { Average age } \\
\text { at operation }\end{array}$ \\
\hline Tendo calcaneus elongation & 77 & 16 & $\begin{array}{c}\text { Tendon transplant } \\
7\end{array}$ & 6 years 11 months \\
\hline Gastrocnemius recession & 53 & 23 & $\begin{array}{c}\text { Partial denervation } \\
20\end{array}$ & 6 years 10 months \\
\hline Tenotomy & 1 & - & - & - \\
\hline
\end{tabular}

TABLE II

Recurrence of Equinus Deformity after Operation

\begin{tabular}{|c|c|c|c|c|}
\hline Operation & $\begin{array}{c}\text { Number of } \\
\text { operations }\end{array}$ & $\begin{array}{c}\text { Operations } \\
\text { needed for } \\
\text { recurrence }\end{array}$ & Percentage & $\begin{array}{c}\text { Average number } \\
\text { of years before } \\
\text { second procedure }\end{array}$ \\
\hline Tendo calcaneus elongation & 77 & 18 & 23 & $4 \cdot 33$ \\
\hline Gastrocnemius recession . & 53 & 8 & 15 & $3 \cdot 5$ \\
\hline Total . . & 130 & 26 & 20 & $3 \cdot 9$ \\
\hline
\end{tabular}

\section{RESULTS}

In the records of the ninety-two patients in this study, a total of 131 primary procedures had been done for equinus deformity. Seven patients who had had elongation of the tendo calcaneus had also had a tendon transfer, either of the tibialis anterior laterally or of the tibialis posterior to the peroneus brevis. Twenty who had had gastrocnemius recession also had partial denervation of the soleus or gastrocnemius. The average age at the time of operation for the two procedures was the same, just under seven years (Table I).

Recurrence-The deformity was considered to have recurred when there was a sufficient limitation of extension and disturbance of limb function to need a second operation. Twentythree per cent of those who had had the tendo calcaneus elongated and 15 per cent of those who had had a gastrocnemius recession had a recurrence (Table II). On average the second operation was done four years and four months after elongation of the tendo calcaneus and three and a half years after gastrocnemius recession. Those patients who needed a second operation had an average age of five years and nine months at the first operation, but for those

VOL. 54 B, NO. 2, MAY 1972 
who did not have a further operation it was seven years and four months. A third operation for recurrent equinus deformity was done in only four patients.

Distribution of paralysis--Table III shows the operations needed and the results in patients with hemiplegia, tetraplegia, paraplegia, monoplegia and athetosis. In hemiplegia, thirty-seven of the forty-two operations were to elongate the tendo calcaneus, for shortening of the whole triceps surae. In paraplegia, gastrocnemius recession was done twice as often as tendo calcaneus lengthening and, in tetraplegia, both were needed equally often. The recurrence rate after tendo calcaneus elongation in hemiplegia was 27 per cent, in quadriplegia it was 17 per cent and in paraplegia it was 33 per cent. The recurrence rate of gastrocnemius recession was 22 per cent in tetraplegia and 4 per cent in paraplegia. The number of gastrocnemius recessions done in hemiplegia was too small for comparison, but two out of five did need a further operation. The better results of gastrocnemius recession in paraplegia were found even though the individual involvement of the lower limb was at least as severe and sometimes more severe than in tetraplegia.

TABLE III

Results of Operations for Equinus Deformity by Distribution of Paralysis

\begin{tabular}{|l|c|c|c|c|c|}
\hline Group & $\begin{array}{c}\text { Number of } \\
\text { patients }\end{array}$ & $\begin{array}{c}\text { Tendo calcaneus } \\
\text { elongation }\end{array}$ & $\begin{array}{c}\text { Repeat operations } \\
\text { after tendo calcaneus } \\
\text { elongation }\end{array}$ & $\begin{array}{c}\text { Gastrocnemius } \\
\text { recession }\end{array}$ & $\begin{array}{c}\text { Repeat operations } \\
\text { after gastrocnemius } \\
\text { recession }\end{array}$ \\
\hline Hemiplegia . & 42 & 37 & 10 & 5 & 2 \\
\hline Paraplegia . & 19 & 12 & 4 & 25 & 1 \\
\hline Tetraplegia . & 27 & 24 & 4 & 23 & 5 \\
\hline Monoplegia . & 3 & 3 & - & - & - \\
\hline Athetoid & 1 & 1 & - & - \\
\hline
\end{tabular}

Because the selection of the operation to be done depends on the difference between the range of ankle extension with the knee in extension and in flexion, an analysis was made of the difference in the range of extension in the two positions of the knee whenever it had been recorded in the examination before operation and was compared in those treated by gastrocnemius recession with those treated by elongation of the tendo calcaneus. The difference in extension was found to be 27 degrees in those limbs treated by gastrocnemius recession and 20 degrees in those having tendo calcaneus elongation, which suggested that the clinical features in tetraplegia and paraplegia were not greatly different. In hemiplegia the difference in range of extension with the knee flexed or extended was only 16 degrees, which almost certainly accounts for the preponderance of tendo calcaneus elongation in this group.

Gait and function-All patients, including monoplegics with slight involvement, walked flatfootedly in bare feet but in most it was barely detectable unless the patient was asked to run. When walking on the flat in normal shoes it was often difficult to detect any abnormality. In thirteen limbs, eight in hemiplegia or monoplegia and five unilaterally in paraplegia, there was persistent equinus with the knee in extension but all had an excellent gait. Ten patients (sixteen feet) showed some inadequacy of push-off and could not rise on to the toes but there was calcaneus deformity in only one patient who had been treated by bilateral gastrocnemius recession, at which time it was possible that the soleus muscle had also been incised accidentally. Of the sixteen calves showing functional weakness, six had had second operations for equinus and two had had a partial neurectomy of the triceps surae at the time of gastrocnemius recession. 
Complications-Four patients who had had tendo calcaneus elongation complained of blistering or of a painful scar in cold weather, but none had disfigurement. One patient-who had had a gastrocnemius recession - had decreased sensibility on the lateral side of the sole of the foot. presumably because of damage to the sural nerve. No weakness of knee flexion was found in any patient who had had a gastrocnemius recession unless a hamstring transfer had been done at the same time or later.

All patients, except possibly the child who developed calcaneus deformity, were significantly improved in function as a result of the correction of equinus.

\section{DISCUSSION}

The success rate of an operation for the treatment of deformity in paralytic conditions should not necessarily be related to the rate of recurrence of the deformity. The examination of muscle activity before operation often confirmed the clinical impression that the liability to recurrence of deformity was greatest in children with persistent functional weakness of ankle extension even after the deformity had been corrected. Elongation of the tendo calcaneus or gastrocnemius recession reduces the power of flexion by one to two grades on the Medical Research Council scale and in over 70 per cent of patients this was sufficient to produce balanced action of extensors and flexors. In legs with a general extension power of grade 2 or less, recurrent deformity could only have been prevented by gastrocnemius or soleus neurectomy in addition to correcting the length of the triceps surae, which would have weakened the calf muscles unjustifiably. In most patients with this amount of functional weakness the likelihood of further deformity after four or five years had been accepted; but even some patients in whom only a gastrocnemius recession had been done, had a slight calcaneus gait because of weak flexion.

One of the main objects of the study was to determine whether or not the operation without bracing afterwards affected the ultimate result. A recurrence rate of 20 per cent is well within the range described in the literature (Green and McDermott 1942, Phelps 1957, Pollock 1962), with the exception of a report by Bassett and Baker (1966) which mentions a 4 per cent recurrence rate but does not state the length of time of follow-up after the operation. Most of our patients had finished growth at the time of this study. Even if the liability to recurrence of equinus were to be diminished by strict and long continued bracing or splintage after operation, it is doubtful if the inconvenience, added weight and clumsiness of the appliance would be justified, because 80 per cent of patients-whatever the severity of their muscle imbalance - maintained an adequate range of extension by their own muscle activity.

The success of gastrocnemius recession as compared with elongation of the tendo calcaneus in paraplegic patients is significant but this investigation offers no explanation for this, although it does show that, when possible, gastrocnemius recession should be done in paraplegic and possibly also in tetraplegic patients.

A small amount of equinus at follow-up was found to be no great detriment, and in hemiplegics was advantageous because it allowed some compensation for inequality of limb length, as noted by Banks and Panagakos (1966) and Staheli, Duncan and Schaefer (1968). Even when some fixed equinus was present on one side in a bilateral case, function was more satisfactory than in those who had weakness of flexion with a tendency to calcaneus gait. This finding confirms the clinical impression that a full range of extension should never be the aim in the management of equinus deformity in cerebral palsy. Whatever the operation, the ankle should be placed at a right angle for plaster fixation rather than in full extension. Partial neurectomy of the gastrocnemius or soleus is probably best avoided at the time of gastrocnemius recession because of its liability to produce calcaneus. It is more satisfactory to do a further operation to correct recurrent equinus than to risk a calcaneus gait or even a calcaneus deformity.

VOL. 54 B, NO. 2, MAY 1972 


\section{CONCLUSIONS}

1. Correction of equinus deformity in cerebral palsy either by elongation of the tendo calcaneus or by gastrocnemius recession gives satisfactory results without splintage or bracing after operation.

2. Gastrocnemius recession is the operation of choice in paraplegic spastic cerebral palsy, and wherever possible in tetraplegic cerebral palsy. In hemiplegia the whole of the triceps surae is usually involved, and elongation of the tendo calcaneus is almost always needed.

3. Correction at operation should aim to result in a mild degree of equinus deformity at the end of the growth period in hemiplegic spastic cerebral palsy. Over-enthusiastic gastrocnemius recession can lead to excessive weakness of the calf in some patients.

\section{REFERENCES}

Banks, H. H., and Panagakos, P. (1966): Orthopaedic Evaluation of the Lower Extremity in Cerebral Palsy. Clinical Orthopaedics and Related Research, 47, 117.

Barnett, H. E. (1952): Orthopedic Surgery in Cerebral Palsy. Journal of the American Medical Association, 150, 1396.

Bassett, F. H., and BAKer, L. D. (1966): Equinus Deformity in Cerebral Palsy. In Current Practice in Orthopaedic Surgery, Volume 3, p. 59. Edited by J. P. Adams. St Louis: The C. V. Mosby Company.

Green, W. T., and McDermott, L. J. (1942): Operative Treatment of Cerebral Palsy of Spastic Type. Journal of the American Medical Association, 118, 434.

McCarroll, H. R., and Schwartzmann, J. R. (1943): Spastic Paralysis and Allied Disorders. Journal of Bone and Joint Surgery, 25, 745.

Phelps, W. M. (1957): Long-term Results of Orthopaedic Surgery in Cerebral Palsy. Journal of Bone and Joint Surgery, 39-A, 53.

Pollock, G. A. (1953): Lengthening of the Gastrocnemius Tendon in Cases of Spastic Equinus Deformity. Journal of Bone and Joint Surgery, 35-B, 148.

Pollock, G. A. (1962): Surgical Treatment of Cerebral Palsy. Journal of Bone and Joint Surgery, 44-B, 68.

SilfVerskiöld, N. (1924): Reduction of the Uncrossed Two-joints Muscles of the Leg to One-joint Muscles in Spastic Conditions. Acta Chirurgica Scandinavica, 56, 315.

Silver, C. M., and Simon, S. D. (1959): Gastrocnemius-muscle Recession (Silfverskiöld Operation) for Spastic Equinus Deformity in Cerebral Palsy. Journal of Bone and Joint Surgery, 41-A, 1021.

Staheli, L. T., Duncan, W. R., and Schaefer, E. (1968): Growth Alterations in the Hemiplegic Child. Clinical Orthopaedics and Related Research, 60, 205.

Stoffel, A. (1913): The Treatment of Spastic Contractures. American Journal of Orthopedic Surgery, 10, 611. Strayer, L. M., Jun. (1950): Recession of the Gastrocnemius. Journal of Bone and Joint Surgery, 32-A, 671. StraYer, L. M., Jun. (1958): Gastrocnemius Recession. Journal of Bone and Joint Surgery, 40-A, 1019.

Vulpius, O., and Stoffel, A. (1920): Orthopädische Operationslehre. Second edition. Stuttgart: Ferdinand Enke. 